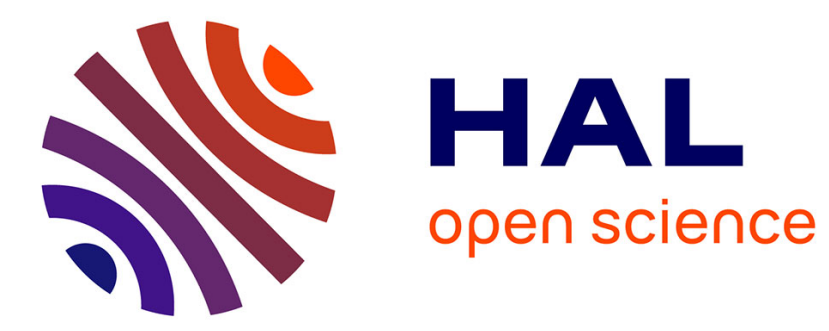

\title{
PANI/ZnO/Quartz structure for Love wave gas sensor
}

F. Moreira, F. Sarry, Dominique Debarnot, O. Elmazria, Fabienne

Poncin-Epaillard

\section{To cite this version:}

F. Moreira, F. Sarry, Dominique Debarnot, O. Elmazria, Fabienne Poncin-Epaillard. PANI/ZnO/Quartz structure for Love wave gas sensor. European Physical Journal: Applied Physics, 2009, 47 (1), pp.1-5. 10.1051/epjap/2009060 . hal-00480165

\section{HAL Id: hal-00480165 https://hal.science/hal-00480165}

Submitted on 3 May 2010

HAL is a multi-disciplinary open access archive for the deposit and dissemination of scientific research documents, whether they are published or not. The documents may come from teaching and research institutions in France or abroad, or from public or private research centers.
L'archive ouverte pluridisciplinaire HAL, est destinée au dépôt et à la diffusion de documents scientifiques de niveau recherche, publiés ou non, émanant des établissements d'enseignement et de recherche français ou étrangers, des laboratoires publics ou privés. 


\title{
PANI/ZnO/Quartz structure for Love wave gas sensor
}

\author{
F. Moreira ${ }^{1}$, F. Sarry ${ }^{1}$, D. Nicolas-Debarnot ${ }^{2}$, O.Elmazria ${ }^{1}$, and F. Poncin-Epaillard ${ }^{2}$ \\ 1 IJL/P2M, Nancy University, Vandœuvre-les-Nancy, France \\ 2 LPCI, Université du Maine, Le Mans, France
}

Received: date / Revised version: date

\begin{abstract}
Everyone knows the importance of sensors in our society and the huge attempt to improve their properties in order to obtain better sensitivity and selectivity. In this paper, we are more particularly focused on gas sensors based on surface acoustic waves (SAW) device. In a previous work, we have developed and studied a structure composed of a $90^{\circ}$ rotated ST quartz crystal covered with a ZnO layer. By developing inter-digital transducers (IDT) on this structure, we can generate different types of acoustic waves. Love waves which are confined near the surface are known to be very sensitives to fluids (liquids or gases). The aim of this work is to present the way we have developed this optimal structure and to test it with a specific polymer. This polymer is polyaniline (PANI). Its main advantage is that it should be deposited by cold pulsed plasma process.
\end{abstract}

PACS. $43.35 . \mathrm{Ns}-43.38 . \mathrm{Fx}-$ 82.35.Lr

\section{Introduction}

Surface acoustic wave (SAW) devices are widely used for filtering applications in mobile telephony. Nowadays they are more and more used in the field of instrumentation and measurement because they are sensitive to many external parameters such as temperature, mechanical deformation, pressure, humidity or gases.

In this paper, we present the results of the development of a gas sensor based on a SAW structure. We first describe the theoretical approach which identify a priori the parameters (crystal cut, thickness, ...) in order to obtain the optimal the structure. We then show experimental results obtained on the optimized $\mathrm{ZnO} /$ Quartz ST-90 ${ }^{\circ}$ Love wave structure. Finally, we test the developed sensor for the detection of nitrogen dioxide $\left(\mathrm{NO}_{2}\right)$ by adding a polyaniline sensitive layer (PANI). 
2 Basic structure of the sensor: $\mathrm{ZnO} /$ Quartz

ST $-90^{\circ}$

\subsection{Theoretical approach of the Love wave}

Love waves which are polarized transverse waves have been shown to present low radiation in fluids and a good sensitivity [1]. In order to obtain these guided waves, it is necessary to deposit a thin layer on a piezoelectric substrate. Moreover, the condition for the existence of Love wave mode is that shear velocity in the layer is smaller than the shear velocity in the substrate. In our device, the shear velocity of the $\mathrm{ZnO}$ layer $\left(V_{C}=2650 \mathrm{~m} / \mathrm{s}\right)$, used as the waveguide layer, is lower than that of the $90^{\circ}$ rotated ST-cut quartz velocity $\left(V_{S}=4996 \mathrm{~m} / \mathrm{s}\right)[2]$. Due to the relatively high velocity contrast between the guided layer and the substrate, it is possible to generate waves with a better confinement near the surface compared to classical structure obtained with $\mathrm{SiO}_{2} /$ Quartz or PMMA/Quartz. Furthermore, the $\mathrm{ZnO}$ film presents a relatively high electromechanical coupling coefficient $\left(K^{2}\right)$ and a negative temperature coefficient of frequency (TCF) leading to a thermally compensated structure when combined with ST-cut quartz [3].

The numerical program was developed in the laboratory by using the Campbell and Jones method [4]. The equations describing the surface acoustic waves propagation in any medium have the following form:

$$
\begin{gathered}
c_{i j k l} \frac{\partial^{2} u_{l}}{\partial x_{j} \partial x_{k}}+e_{k i j} \frac{\partial^{2} \Phi}{\partial x_{j} \partial x_{k}}=\rho \frac{\partial^{2} u_{l}}{\partial t^{2}} \\
e_{j k l} \frac{\partial^{2} u_{l}}{\partial x_{j} \partial x_{k}}-\epsilon_{j k} \frac{\partial^{2} \Phi}{\partial x_{j} \partial x_{k}}=0
\end{gathered}
$$

where $c_{i j k l}, e_{k i j}$ and $\epsilon_{j k}$ are respectively the elastic, piezoelectric and dielectric tensors. $\rho$ is the mass density. The initial program is subsequently modified in order to take into account Love waves. The Christoffel matrix obtained from the first equations is divided into two sub-matrix for both quartz and zinc oxide [5]. Theoretical calculations were used to determine the dispersive curves of phase velocity $(\mathrm{V}), K^{2}, \mathrm{TCF}$, and mass sensitivity as a function of $\mathrm{ZnO}$ normalized thickness $\left(k h_{Z n O}=2 \pi h / \lambda\right)$. The electromechanical coupling coefficient reflects the ability of the material to convert the mechanical energy into electrical energy and vice versa. It is defined by the following equation:

$$
K^{2}=\frac{V_{0}^{2}-V_{m}^{2}}{V_{0}^{2}}
$$

where $V_{0}$ is the phase velocity on the open circuit (free surface) and $V_{m}$ is the phase velocity of the short-circuit (metallized surface). The theoretical temperature coefficient of frequency was estimated by the equation :

$$
T C F=\frac{1}{f} \frac{\Delta f}{\Delta T}=\frac{V(T)-V\left(T_{0}\right)}{V\left(T_{0}\right)}-\alpha_{i j}
$$

with $f$ the central frequency, $\Delta f$ the frequency shift observed for a temperature variation $\Delta T . V(T)$ and $V\left(T_{0}\right)$ are phase velocities at $T$ and $T_{0}$ (reference temperature) respectively. $\alpha_{i j}$ is the thermal expansion coefficient of $\mathrm{ZnO}$ along the SAW propagation direction. The obtained simulations [6] have enabled us to extract the value of the normalized $\mathrm{ZnO}$ thickness, which provides temperature compensation and a better $K^{2}$. We therefore get $k h_{Z n O}=0.55$. 
To determine the sensitivity to the mass effect, we take into account the work of Mc Hale [7]. His theoretical method takes into account the theory of disturbances developed by Auld [8]. In the case of a three layer system consisting of a sensitive layer and the $\mathrm{ZnO} / \mathrm{Quartz}$ structure, the mass sensitivity should be given by the following formula:

$$
S_{m}=\frac{1}{\rho_{l}}\left[\frac{1-V_{p}^{2} / V_{0}^{2}}{1-V_{l}^{2} / V_{0}^{2}}\right] \frac{f_{0}}{V_{l}}\left(\frac{d \ln (V)}{d z}\right)_{z=z_{0}}
$$

where $V_{p}$ and $V_{l}$ are respectively the velocity in the sensitive layer and in the guiding layer. $z_{0}$ is the guiding layer thickness $\left(z_{0}=d / \lambda\right)$ at the operating point. Due to the very small thickness of the sensitive layer (less than $1 \%$ of the wavelength) and the choice of the Love wave (confinement of the wave in the $\mathrm{ZnO}$ layer), it is possible to determine the mass effect sensitivity without considering the sensitive layer. We therefore modify the previous equation by substituting $V_{p}$ with $V_{l}$.

Figure 1 presents the theoretical result where the maximum mass sensitivity is obtained for $k h_{Z n O}=0.25$. The value of $k h_{Z n O}=0.55$ will give us a sensitivity of 0.4 which is $30 \%$ less than the maximum. Nevertheless for that value, we will also have a temperature compensation and a better $K^{2}$.

\subsection{Experimental results obtained on the developed} structure.

Figure 2 shows the frequency response observed with the structure based on the theoretical approach. We note that, as expected, it appears a response corresponding to the

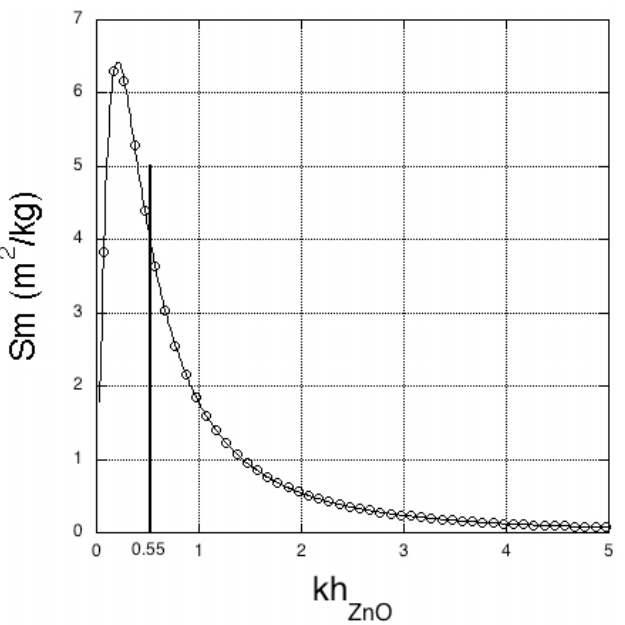

Fig. 1. Theoretical mass sensitivity determination versus normalized $\mathrm{ZnO}$ thickness.

Rayleigh wave at $475 \mathrm{MHz}$. This peak should be associated to the pure Rayleigh wave generated by the $\mathrm{ZnO}$ layer. Two peaks $(507 M H z, 823 M H z)$ are due to the Love wave generated by the pure shear wave of the quartz ST- $90^{\circ}$ and the guiding layer. Although the mode 1 of the Love wave presents fewer losses than the mode 0 , we better use the mode 0 because it is less sensitive to temperature variation.

To study the temperature coefficient of the frequency, we develop series of $\mathrm{ZnO} /$ Quartz ST-90 ${ }^{\circ}$ structures with different wavelengths. We then test each of them as a function of the temperature. Figure 3 shows the obtained responses. We note that the theory is in good agreement with experimental. Moreover for a $k h_{Z n O}$ of around 0.55 , we have a temperature compensation as it was predicted. 


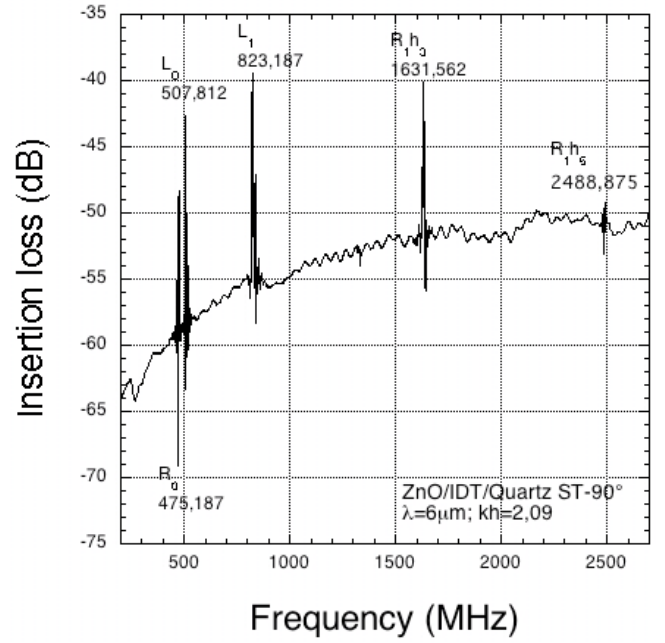

Fig. 2. Frequency response of the $\mathrm{ZnO} / \mathrm{Quartz}$ ST$90^{\circ}$ structure with a IDT periodicity of $6 \mu \mathrm{m}$

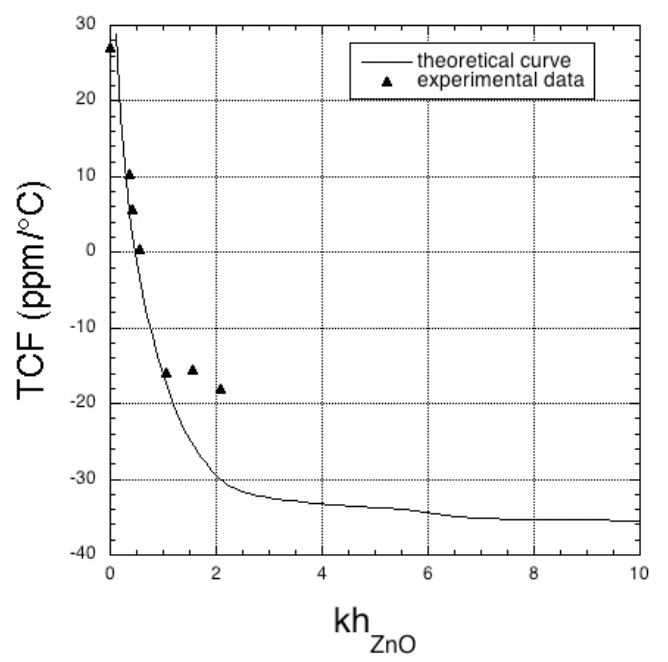

Fig. 3. Temperature coefficient of frequency versus $\mathrm{ZnO}$ normalized thickness. Experimental and theoretical results.

\section{Gas sensor development}

\subsection{Polyaniline sensitive layer}

To detect gaseous compounds, it is necessary to add a sensitive layer on the wave path in order to measure perturbations. The layer must present the best affinity with the compound to detect. Polymers are nowadays increasingly

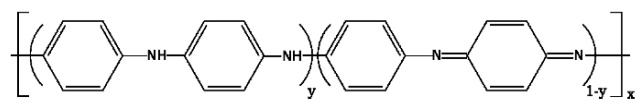

Fig. 4. General structure of polyaniline

used because they offer a wide variety of properties and a significant adaptability by chemical treatment. Conducting polyaniline (PANI) exhibits extraordinary electronic properties, such as low ionization potential and high electron affinity. As a result, it can be easily reduced or oxidized. PANI has wide variety of applications in batteries, electromagnetic devices, biosensors, gas-separating membranes, electromagnetic shielding, and antistatic materials. That is why we choose to use the polyaniline (Fig. 4). Besides, it was shown that post-treatment can improve sensitivity to certain species [9]. PANI is mostly synthesized by aniline oxidation either with a chemical oxidant (chemical route) or through electrochemistry. The method used here is a plasma polymerization [10]. Films are deposited in a pulsed plasma $\mathrm{RF}$ reactor with a time of discharge of tenth of a millisecond. The power generator is set at $80 \mathrm{~W}$ and the vacuum pressure is of $3.10^{-6} \mathrm{Torr}$. The aniline monomer liquid is contained in a glass jar at room temperature and sprayed into the vacuum chamber during deposition. The pressure in the reactor is maintained at 0.02 Torr during curing. In order not to perturb the wave propagation and the basic structure, we have limited the thickness of the deposited film to a hundredth of the wavelength. Thus PANI films have a thickness of $265 n m \pm 7 n m$, thickness obtained within 30 minutes. Figure 5 shows the final structure. In Figure 6, we present the 


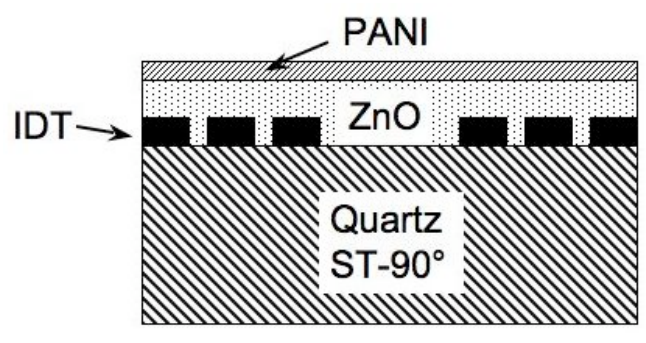

Fig. $\quad 5 . \quad$ Complete SAW structure: $\mathrm{PANI}(265 \mathrm{~nm}) / \mathrm{ZnO}(2.1 \mu \mathrm{m}) /$ Quartz ST-90 ${ }^{\circ}$.

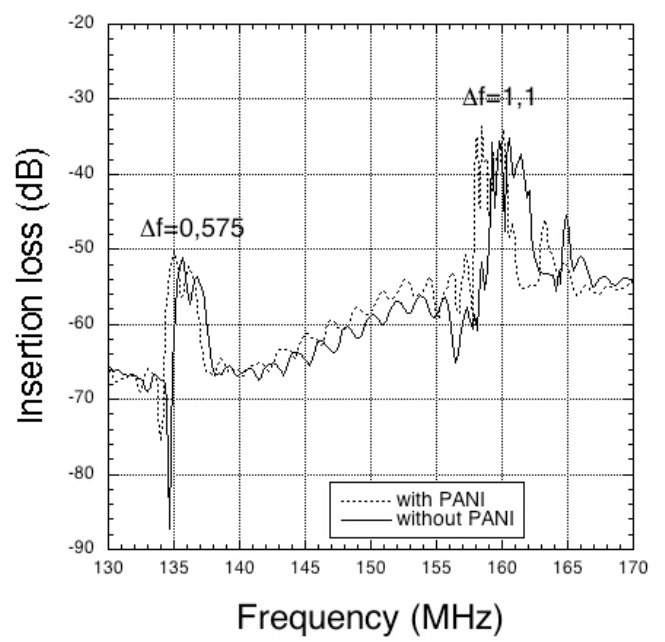

Fig. 6. Frequency response of the $\mathrm{ZnO} /$ Quartz ST- $90^{\circ} \mathrm{SAW}$ device with and without PANI.

frequency response of the $\mathrm{ZnO} /$ Quartz $\mathrm{ST}-90^{\circ} \mathrm{SAW}$ device substrate with and without a polyaniline film $265 \mathrm{~nm}$. The wavelength is fixed to $24 \mu m$, covered with a $\mathrm{ZnO}$ layer of $2.1 \mu \mathrm{m}$. We first find that the experimental velocities correspond to theoretical velocities, $3250 \mathrm{~m} / \mathrm{s}$ for the Rayleigh wave and $3826 \mathrm{~m} / \mathrm{s}$ for the Love wave against $3335 \mathrm{~m} / \mathrm{s}$ and $3926 \mathrm{~m} / \mathrm{s}$, respectively, for the theoretical values. These divergences should be due to the mass effect caused by the PANI layer. We note that the PANI layer perturbs slightly the frequency response. Indeed, the insertion losses are quite similar.

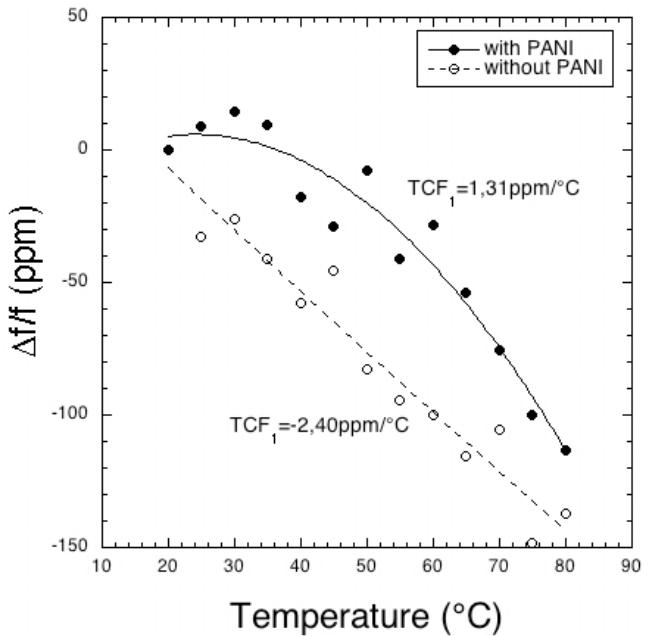

Fig. 7. Frequency shift versus temperature of the developed structure with and without PANI.

With regard to the temperature stability (Fig. 7), there are some variations between theoretical and experimental data. For both structures, this should be related to the technological dispersion of the $\mathrm{ZnO}$ characteristics and to constant values used for the theorectical determination. Moreover, the addition of the PANI layer improves the temperature compensation of $45 \%\left(T C F_{\text {withoutPANI }}=\right.$ $\left.2.4 p p m /{ }^{\circ} C ; T C F_{\text {withPANI }}=1.31 p p m /{ }^{\circ} C\right)$.

\subsection{First gas test results}

Nitrogen dioxide $\left(\mathrm{NO}_{2}\right)$ was chosen to be tested. It is part of $N O_{x}$ family which is harmful to the environment as well as sulphur dioxide $\left(\mathrm{SO}_{2}\right) \cdot \mathrm{SO}_{2}$ may also appear and alter microsystem process. Experimental set-up is based on a permeameter for low concentration generation and mass flowmeters to control the flow and further dilute the gas test. Figure 8 and 9 represent the frequency shift of the PANI/ZnO/Quartz ST-90 after many gas introduc- 


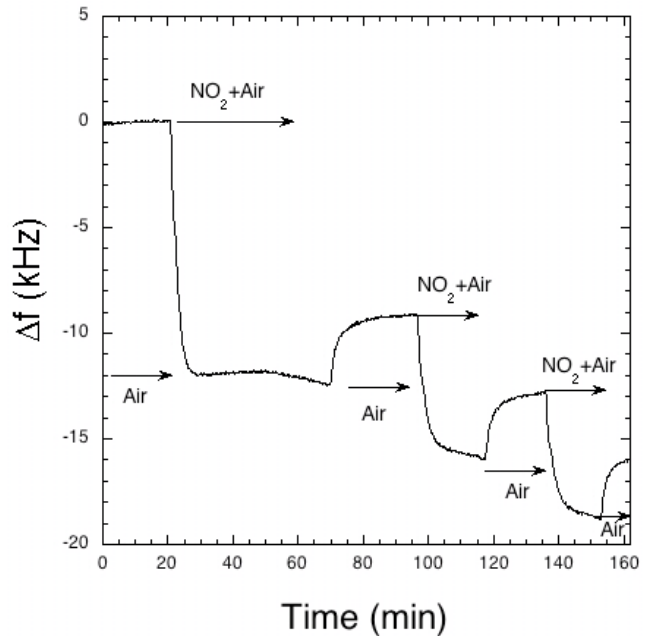

Fig. 8. Frequency shift versus time after $\mathrm{NO}_{2}$ introduction $(54 p p m)$.

tion cycles $\left(\mathrm{NO}_{2} /\right.$ Dry Air and $\mathrm{SO}_{2} /$ Dry Air $)$. For each of the two tested gases, we observe a frequency variation corresponding to the variation of the Love wave velocity due to the mass effect. The frequency variation is about $6 \mathrm{kHz}$ for a $\mathrm{NO}_{2}$ concentration of $54 \mathrm{ppm}$. This variation is ten times higher than that obtained without the layer of PANI for the same concentration. This sensitivity should be enhanced by functionalizing the polymer. This polymer presents a lack of selectivity because it reacts also to other gases like $\mathrm{SO}_{2}$ (Fig. 9). We note also on the two curves a short term drift of the baseline, opposited for $\mathrm{NO}_{2}$ and $\mathrm{SO}_{2}$. This should be attributed to the airflow circulation on the device generating a higher gas concentration

\section{Conclusion and outlook}

We have developed a surface acoustic wave device with good characteristics in terms of $K^{2}, T C F$ and mass sensitivity. The use of this structure for the detection of gas

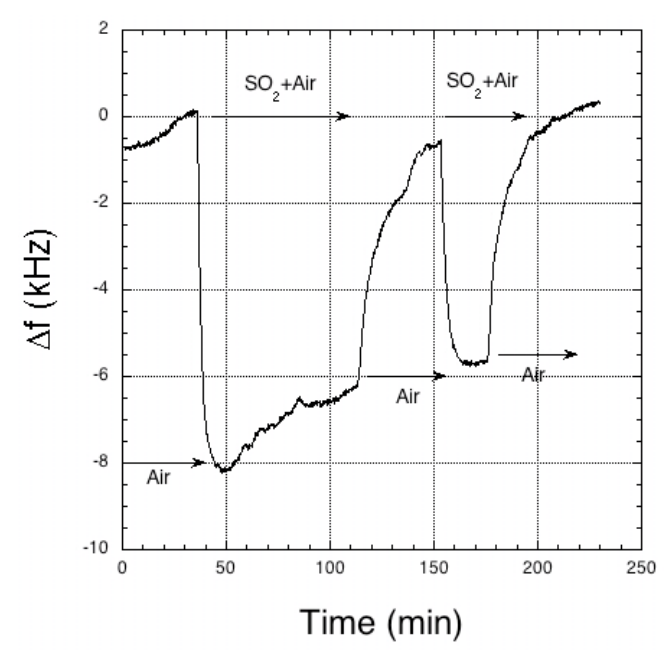

Fig. 9. Frequency shift versus time after $\mathrm{SO}_{2}$ introduction $(34 p p m)$.

requires a sensitive layer. The choice of polyaniline polymer offers an opportunity because this may be functionalized thereafter. It will then be possible to create, from the same initial structure, a set of different sensors. We should then produce a gas sensor array. Moreover the plasma deposition process also offers the advantage of simultaneously deposit $\mathrm{ZnO}$ and PANI without contamination of the guiding layer.

\section{References}

1. Kalantar-Zadeh K., Chen Y.Y., Fry B.N., Trinchi A., Wlodarski W., IEEE Ultrasonics Symposium, (2001) 353-356.

2. Kalantar-Zadeh K., Powell D.A., Wlodarski W., Ippolito S., Glatsis K., Sensors and Actuators B 91, (2003) 303-308.

3. Kadota M., Journal of Applied Physics 36, (1997) 30763080.

4. Campbell J.J., Jones W.R., IEEE Sonics Ultrason. SU-15, (1968) 209-217. 
5. Royer D., Dieulesaint, Ondes Elastiques dans les Solides -

Tome I: Propagation libre et guidée (Masson, 1996).

6. Moreira F., El Hakiki M., Sarry F., Le Brizoual L., Elmazria O., Alnot P., IEEE Sensors Journal 7, (2007) 336-341.

7. McHale G., Newton M.I., Martin F., Journal of Applied Physics 91, (2002) 9701-9710.

8. Auld B.A., Acoustic field and waves in solids (Publishing Compagny, 1990).

9. Nicolas-Debarnot D., Poncin-Epaillard F., Analytica Chimica Acta 475, (2003) 1-15.

10. Nicolas-Debarnot D., Poncin-Epaillard F., ISPC-17 Proceedings 9 (2005). 